BLS 32, No 2 2006. DOI: http://dx.doi.org/10.3765/bls.v32i2.3492

(published by the Berkeley Linguistics Society and the Linguistic Society of America)

\title{
The Role of Animacy in Teiwa and Abui (Papuan)
}

\author{
MARIAN KLAMER and FRANTIŠEK KRATOCHVÍL \\ Leiden University
}

\section{Introduction}

In this paper we discuss the role of animacy in the grammar of Teiwa and Abui, two Trans New Guinea languages spoken on two small islands just north of Timor in Eastern Indonesia. Teiwa has approximately 6,000 speakers on Pantar island, and Abui has approximately 16,000 speakers on Alor island. The paper is based on primary data collected on site in 2003-2005 (cf. Klamer, in prep.; Kratochvíl, in prep.).

While it is common to find pronominal affixes on verbs in Papuan languages, Teiwa and Abui represent the small minority of Papuan languages that only affix transitive objects (P), not subjects (A) (Foley 1986:102-104, Foley 2000:377). The alignment system of Teiwa is nominative-accusative, while Abui has an agentive alignment system. ${ }^{1}$ In both languages, $\mathrm{A}$ is expressed as an independent NP in preverbal position. Ps always occur in between $A$ and V, either as a lexical NP or as a verbal prefix, or as both. In this paper, we focus on the prefixation of $\mathrm{P}$ and show how it is influenced by the animacy value of the referent of $P$.

Animate entities are a salient conceptual category. In first language acquisition, the animacy of entities plays an important role: animate entities are the first to be noticed by young infants, the first objects to be individualized, and nouns referring to animate entities make up the majority of the first lexical items that children acquire (cf. Gentner 1982, Gentner and Boroditsky 2001).

Apart from playing a role in the acquisition of words, animacy also determines aspects of the grammatical system of languages. In the verbal domain, it may determine pronominal agreement or cross-reference patterns, as in those languages where animate objects are marked on the verb, while inanimate objects are not so marked. This results in grammatical systems that are grammatically 'asymmetrical' (Ortmann 1998), also referred to as 'differential object marking' (Bossong 1991, Aissen 2003). Examples of languages with asymmetrical systems

\footnotetext{
${ }^{1}$ Abui marks Undergoers (P and $\mathrm{S}$ of stative intransitives) with prefixes, in contrast to Actors (A and $\mathrm{S}$ of intransitive motion verbs), which are marked with free pronouns. An auxiliary verb construction may also be used to encode A (see Kratochvil, in prep., for more information).
} 


\section{Marian Klamer and František Kratochvíl}

are Swahili, Palauan (Austronesian), Plains Cree (Algonquian) (Ortmann 1998:71-73), and the Papuan languages Usan (Reesink 1987:108-109) and Nggem (Etherington 2002). In this paper, we suggest that Teiwa and Abui are grammatically asymmetrical in a similar way.

In the nominal domain, animacy is one of the most important underlying principles for morphological gender and noun class systems. For example, animacy plays a role in the morphological gender systems of languages like Latin or Czech, and many Papuan languages divide nouns into subclasses of animates vs. inanimates and/or humans vs. non-humans (cf. Foley 2000:371-372 for examples). The languages discussed in this paper have neither morphological gender nor noun classes, but animacy plays an important role in the domain of nominal possession. Teiwa and Abui make a formal distinction between possessors that can be separated from the possessee and those that cannot (alienable vs. inalienable possession). The former are obligatorily marked; the latter are optional. Alienable possessors occur with common nouns, while kinship terms ('father', 'son') and body part nouns ('arm', 'leg') are inalienably possessed. We will suggest that the different marking of alienable vs. inalienable possessor goes back to its animacy. While common nouns may be used with or without a possessor (animate or inanimate), kinship and body part nouns only exist in relation to a possessor that is animate - $\mathrm{a}$ father is always a father to someone else; a leg always belongs to an animate entity. In other words, alienable possessors may be animate or not, but inalienable possessors are always animate, and this distinction is expressed in Teiwa and Abui by using different possessor marking patterns for each type.

In Teiwa and Abui, Ps and possessors are marked with homophonous prefixes. A more general aim of this paper is thus to introduce some languages that encode verbal objects and nominal possessors with prefixes from the same paradigm. This formal similarity contrasts with the more commonly observed one, where As and possessors are marked in the same way (e.g. Bittner and Hale 1996:60). The formal similarity between objects and possessors in Teiwa and Abui is not a coincidence, but depends on the semantic properties of these arguments as being animate or not. We will see that animacy overrides the two factors commonly considered to be the determiners of agreement. Neither the grammatical relation of $\mathrm{P}$ nor its thematic role determines its encoding on the verb; only its animacy value does. $^{2}$

In section 1, we discuss the role of animacy in the marking of Teiwa objects and possessors, followed by a similar discussion of Abui in section 2. In section 3, we summarize the data and discuss the implications. Note that in describing the role of animacy, we focus on third-person pronominals since animacy is a relevant category for third-person referents only, first- and second-person referents being intrinsically animate.

\footnotetext{
${ }^{2}$ In section 2, we will see that in Abui P marking there are additional factors at work, but we will focus on the role of animacy.
} 


\section{Animate Objects and Possessors in Teiwa}

In (1), the third-person singular pronominal forms to mark Ps and possessors in Teiwa are given.

(1) Teiwa $3^{\text {rd }}$ singular pronominals for $\mathrm{P}$ and Possessor

$\begin{array}{llll}P & & \text { Possessor } & \\ \text { Inanimate } & \text { Animate } & \text { Inalienable } & \text { Alienable } \\ \text { ga'an } & g(a)_{-}{ }^{3} & \text { obligatory } g(a-) & \text { optional } g(a) \text { - }\end{array}$

While all Teiwa Ps can be expressed as independent pronouns, only animate Ps may be prefixed. In (2a), the referent of $g a$ - can only be interpreted as an animate entity, while the referent of the pronoun $g a^{\prime}$ 'an in (2b) is typically interpreted as inanimate (it allows an animate reading when it is used with emphatic stress).
a. A ga-regan.
3SG 3-ask
'He asks him.'
b. A ga'an regan.
3SG he/her/it ask
'He asks it.' (or: 'He asks HIM.')

Animate referents also include animals. The concept of animacy is taken literally. In (3a), the definite, human object of 'to bury' is expressed with a pronoun, since a dead person is inanimate. This object cannot be marked with a prefix, as shown in (3b), which was rejected by consultants as having the "very strange" meaning that a living person was to be buried. $\begin{array}{lllll}\text { a. Na } & \text { ta } & \text { ma } & \text { ga'an } & \text { taraxa'. } \\ \text { 1SG } & \text { ASP } & \text { come } & \text { he/her/it } & \text { bury }\end{array}$ 'I come to bury him.'
b. *Na ta ma ga- taraxa'. $1 \mathrm{SG}$ ASP come 3- bury not good for: 'I come to bury him.'

Some transitive verbs typically have animate arguments, examples including the verbs in (4a); others typically have inanimate arguments, examples in (4b); and some occur as often with animates as with inanimates, as those in (4c).

\footnotetext{
${ }^{3}$ The brackets indicate that a prefix has two allomorphs: a syllabic form, which attaches to consonant-initial verbs/nouns, and a consonantal form which attaches to vowel-initial verbs/nouns.
} 


\section{Marian Klamer and František Kratochvíl}

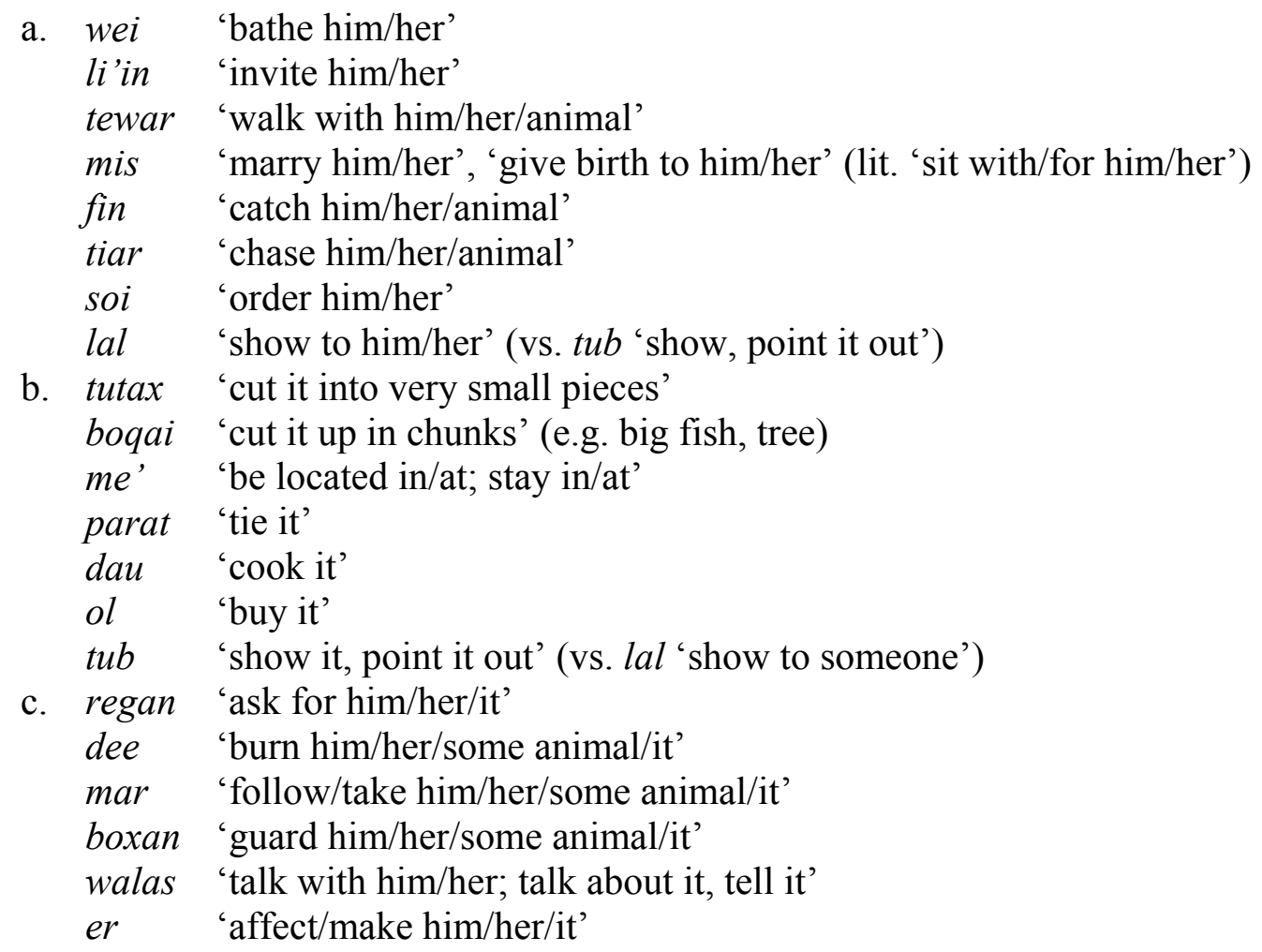

Observe that the animate Ps of the verbs in (4a) have various semantic roles, including Patient, Benefactive, Recipient, Addressee, and Comitative. These roles overlap with those of the inanimate Ps of the verbs in (4b). Despite this overlap in semantic roles, a $\mathrm{P}$ is only prefixed when it has an animate referent (i.e. the verbs in (4a) take object prefixes; those in (4b) do not). Animacy is thus the relevant trigger for encoding an argument on the verb, and not its grammatical relation nor its thematic role.

The translations of some of the verbs in (4c) show that the animacy value of $\mathrm{P}$ can alter the interpretation of the verb. This is also illustrated in (5).
a. $\mathrm{Na}$ ga'an mar.
1SG 3 take
'I take/get it.'
b. $\mathrm{Na}$ ga- mar.
1SG 3- follow
'I follow him/her.'

It should be remarked here that Teiwa has a tiny class of transitive verbs that always express $\mathrm{P}$ with a prefix. These verbs also distinguish Ps according to their animacy value by using different prefixes: a CVC prefix refers to animates, and a CV to inanimates. Examples include wulul 'speak, talk, tell' and wultag 'talk': 


\section{The Role of Animacy in Teiwa and Abui (Papuan)}
a. ga'- wulul
'talk with/tell him/her'
ga- wulul
'talk about it, tell it'
$\begin{array}{lll}\text { b. } & \text { ga'- } & \text { wultag } \\ \text { ga- } & \text { wultag (or [gultag]) }\end{array}$
'talk to/about him/her, tell him/her'
'talk about it'

In sum, in Teiwa, verbal agreement does not mark objects as such, but is crucially determined by the animacy value of the object. The thematic role of the object is irrelevant, as long as it is not an agent.

Turning now from verbal to nominal agreement, let us consider Teiwa possessor marking. Teiwa body part nouns ('arm', 'leg', 'stomach') and kinship terms ('mother', 'son') have an inalienable possessor, and they can only occur with a possessor prefix. This is illustrated in $(7 \mathrm{a}, \mathrm{b})$. Common nouns ('house', 'mountain', 'milk') have an alienable possessor, and as such, possessors are not obligatory; common nouns can occur in isolation without a possessor marker, illustrated in $(7 \mathrm{c}, \mathrm{d})$.
a. ga- xala'
3- mother
b. *xala'
'his/her/their mother'
mother
c. ga- yaf
3- house
d. yaf
'his/her/their house'
‘(a) house/houses'

As mentioned in the introduction, we suggest that there is a fundamental distinction between kinship terms and body part nouns on the one hand, and common nouns on the other: the former exist only in relation to a possessor that is animate, while the latter may have no possessor, or one that is inanimate. In Teiwa, this distinction is expressed morphosyntactically by using an obligatory vs. optional possessor prefix.

In sum, animacy plays a similar role in the verbal and nominal agreement of Teiwa: just as an animate $\mathrm{P}$ is expressed as a verbal core argument by an obligatory prefix on the verb, so is an animate possessor expressed as a nominal core argument by an obligatory prefix on the noun. The prefixes that are used are homophonous.

\section{Animate Objects and Possessors in Abui}

Abui has a group of transitive verbs that typically occur with an inanimate object, and do not require a P-marking prefix. Some examples are given in (8) (cf. the comparable Teiwa verbs in (4).

$$
\begin{array}{ll}
\text { bang 'carry it' } \\
\text { telang } \\
\text { tadia 'pull it' }
\end{array}
$$




\section{Marian Klamer and František Kratochvíl}

$\begin{array}{ll}\text { tukong } & \text { 'cut at it, cut in pieces' } \\ i & \text { 'put it' } \\ \text { bai } & \text { 'hit, grind it' } \\ \text { takai } & \text { 'steal it' } \\ \text { meng } & \text { 'wear it' } \\ \text { mi } & \text { 'take it' }\end{array}$

Abui also has a class of verbs that can have an animate or inanimate object. These verbs do require a $\mathrm{P}$ prefix, and they mark the animate/inanimate character of the $\mathrm{P}$ by choosing a different prefix. Abui uses three sets of prefixes to encode $\mathrm{P} .{ }^{4}$ They are given in (9), which also presents the prefixes marking inalienable and alienable possession. Note that these are identical to two of the P-markers.

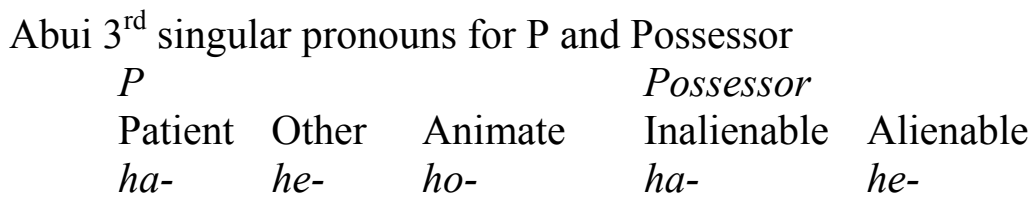

The first set of P-marking prefixes, glossed here as PAT(ient), marks prototypical Patients, entities that undergo a change of state or condition (cf. Dowty 1991:572-573, Van Valin and LaPolla 1997:85). This entity may be animate or inanimate. Sets two and three mark Ps that do not undergo a change of state. Set three is glossed ANIM(ate) since it typically marks animate Ps. Set two contrasts with the first PAT set because it marks Ps that do not undergo a change of state, and it contrasts with the third ANIM set because it typically (though not exclusively, see (12h)) encodes inanimates. To indicate that it marks neither typical patients nor typical animates, it is glossed here as OTHER. ${ }^{5}$ In (10) the distinctions between the paradigms are represented.

${ }^{4}$ The three sets probably derive from one original prefix, $h$-. Synchronically, Abui has a rich array of generic verbs that consist of a single consonant or vowel, including the verbs $a$ 'be at', $e$ 'add', and $o$ 'point' (cf. Kratochvíl, in prep.). Originally, $h$ - may have been used to mark Ps and Possessors, fusing over time with the generic verbs it often attaches to. As a result of reanalyzing the morpheme boundaries, as in (i) below, there are now three distinct prefixes, each with their own semantics.
a. h-a fanga $>$ 3-BE.AT tell $>$ ha-fanga 'tell/order him'
b. h-efanga $>$ 3-ADD tell $>$ he-fanga 'say it'
c. h-o fanga > 3-POINT tell > ho-fanga 'scold him'

One function of generic verbs in Abui is to introduce additional arguments into a clause. In the development of $h a-$, he-, and ho-, the semantics of the generic verb may have fused with the referential properties of the pronominal prefix. In other Trans New Guinea languages such as Dani (Lower Grand Valley, Bromley 1981) and Ekagi (Drabbe 1952), cognate forms of similar generic verbs have also fused with the pronominal prefix.

${ }^{5}$ This label is used for expository reasons here; Kratochvíl (in prep.) employs a different label. 
(10)

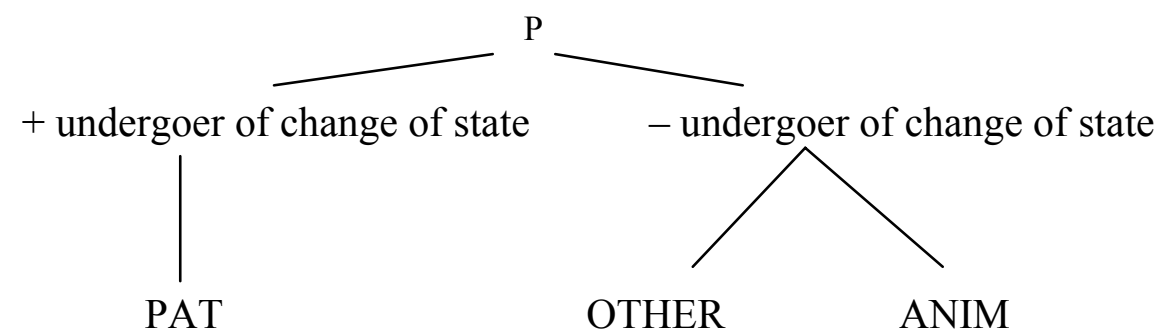

The verb fanga 'say' combines with all three prefixes. In (11a), the order is given and carried out by the patient Simon, who thus undergoes a change of state. In (11b), the prefix refers to the inanimate complement of 'say'. In (11c), the prefix has an animate referent, the addressee or malefactive participant of the scolding.
a. He-
maama
Simon ha-
fanga.
3.AL- father S.
3.PAT
say
'His father ordered Simon.'
b. Ama he- kang he- fanga.
person 3.OTHER can 3.OTHER say
'People agree/approve.' (lit. 'Persons say it can.')
c. A neng loku ho- fanga.
you.SG man PL 3.HUM say
'You scold at the men.'

More examples illustrating the contrasts are given in (12).
a. ha-fanga
3.PAT-tell/say
'order him'
he-fanga
3.OTHER-tell/say
'say it'
ho-fanga
3.ANIM-tell/say
'scold (at) him'
b. ha-lia
3.PAT-fly
'shoot it'
he-lia
ho-lia
3.OTHER-fly
'fly at it'
3.ANIM-fly
'fly at him'
c. *ha-faaling
3.PAT-listen
he-faling
3.OTHER-listen
'listen to it'
ho-faling
3.ANIM-listen
'listen to him'
d. *ha-fahak
3.PAT-hug
he-fahak
3.OTHER-hug
'embrace it'
ho-fahak
3.ANIM-hug
'hug him' 


\section{Marian Klamer and František Kratochvíl}

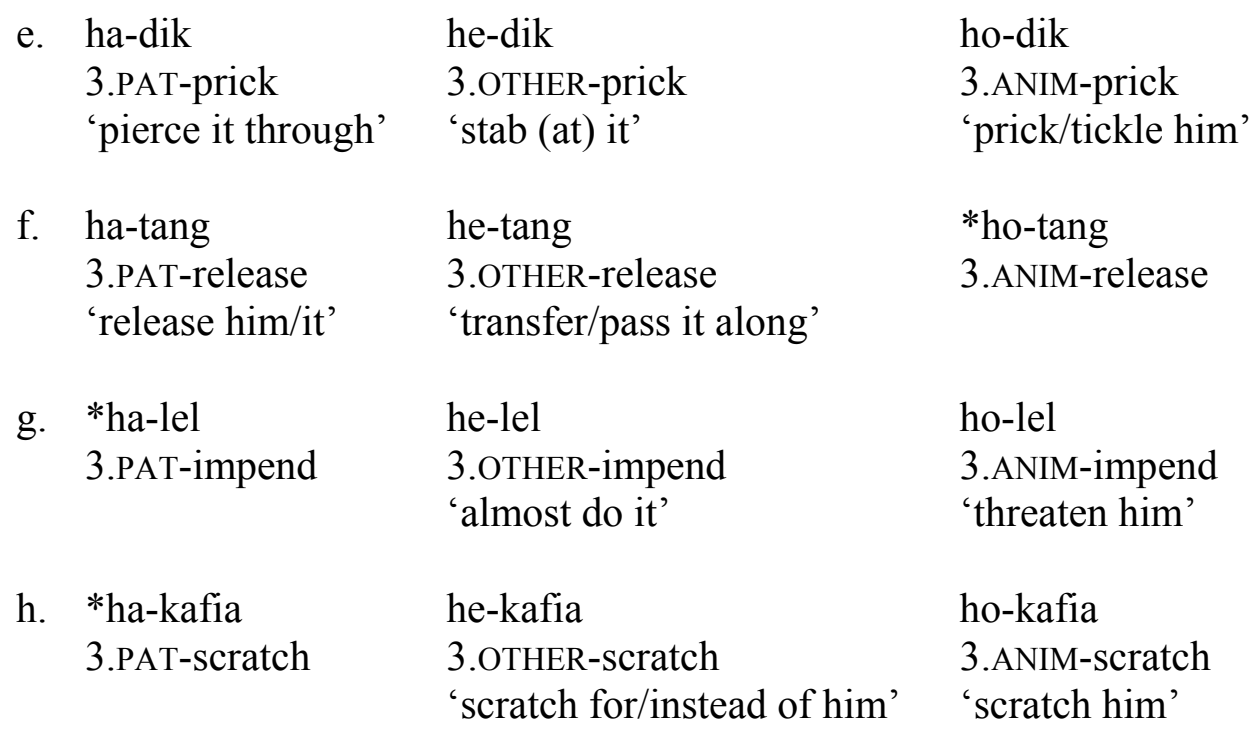

On the basis of these examples, the following observations can be made.

(i) The distribution of the prefixes cannot be determined by looking at the thematic role of the argument because the roles of he- in the middle column overlap (to some extent) with the roles of $h a$ - and ho-. The thematic role of $h a$-is patient; the thematic role of he- is theme in (a,c,f), goal in (b), location in (d), patient (without change of state) in (e), and benefactive in (h). The thematic roles referred to by ho- include malefactive, benefactive, or goal; all of the referents are animate.

(ii) The $h a$ - form refers to a real patient in the sense that it must undergo a change of state, while the he-form does not. This is clear from the ungrammatical forms in $(\mathrm{c}, \mathrm{d}, \mathrm{h})$ : the $\mathrm{P}$ of these verbs does not undergo a change of state, hence no $h a$ - form is possible. In (e), the referent of $h a$ - is the most affected $\mathrm{P}$; it really underwent a change of state, while the referent of he-did not.

(iii) Some forms are not allowed because they would denote semantically unusual concepts. For example, in (f) no ho- form is allowed because 'to release on someone' is semantically strange. In ( $\mathrm{g}$ ) no ha-form is allowed because an event that is 'about to happen' by definition does not have a Patient that undergoes a change of state because nothing has happened to $P$ yet.

(iv) Ho- only refers to animate Ps. However, not all animate Ps are marked by ho-: they are encoded by $h a$ - when they undergo a change of state, as in $(\mathrm{a}, \mathrm{f})$, or when they are benefactive, as in (h). Thus, animacy is a crucial feature of the referents of ho-, but it does not play a role in the choice of 


\section{The Role of Animacy in Teiwa and Abui (Papuan)}

$h a-$, while the choice of he- vs. ho- is determined by animacy to some extent.

Further evidence for the analysis of ho- as referring only to animates comes from the marking of the animate $\mathrm{S}$ of intransitive verbs that denote states or experiences. In (13a), the $\mathrm{S}$ is the animate experiencer of lil 'hot' and must be marked with ho-. In contrast, an inanimate $\mathrm{S}$ of the same verb is expressed as a lexical NP, as shown in (13b).
a. Ho- lil- a.
3.ANIM- hot be.at
'S/he feels hot.'
b. Kopi do lil- a.
coffee DET hot be.at
'This coffee is hot.'

Note that the he- prefix may be used with lil when it refers to a possessor, as in (14a), and a $h a$ - prefix refers to the patient of the derived construction 'to give heat' > 'to heat up', as in (14b).
a. He- lil -a
3 hot be.at
'his warmth/blessing/knowledge of life' (referent of he- is possessor)
b. Ha- lil $-\mathrm{r} \quad$-a.
3.PAT hot give be.at
'Heat it up.' (lit. 'Give it heat.') (referent of $h a$ - is patient)

In the nominal domain, Abui distinguishes between alienably and inalienably possessed nouns. The inalienable nouns have an obligatory possessor. Body parts mark their possessor with $h a$-; kin terms mark it with $h e-$. This is illustrated in $(15 \mathrm{a}, \mathrm{b})$. The possessor prefix of alienable nouns is also he-, but unlike for kin terms, it is optional for common nouns. This is shown in $(15 \mathrm{c}, \mathrm{d})$. Nominal attributive constructions as in (15e) may have a possessor interpretation, but do not have a possessor prefix. ${ }^{6}$

\footnotetext{
${ }^{6}$ In Teiwa and Abui, certain locations may be expressed with a nominal possessive construction involving a possessed body part noun (e.g. Abui: fala ha-po 'house 3-forehead' > 'in front of the house'). In such constructions, the prefix obviously has an inanimate possessor referent. We see this as metaphorical extensions of the original possessor constructions with body part nouns, which always have animate possessors.
} 


\section{Marian Klamer and František Kratochvíl}

(15)
a. ha-to
ha-ne
ha-muk
b. he-wil
he-hai
c. he-fala
he-konrek
d. fala
konrek
e. aremang fala
tribe house 'tribal house'

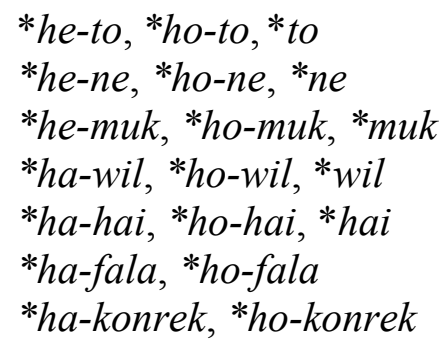

Abui possessor marking prefixes are thus homophonous with the prefixes that mark Ps. Note, however, that their function in the verbal and nominal domain is not parallel.

$\begin{array}{lll} & \text { Verbal Domain } & \text { Nominal Domain } \\ \text { ha- } & \text { patient } & \text { inalienable poss. of body parts: obligatory } \\ \text { he- } & \text { various roles } & \begin{array}{l}\text { inalienable poss. of kinship: obligatory } \\ \text { alienable poss.: optional } \\ \text { not used }\end{array}\end{array}$

To conclude, inalienable nouns are inherently possessed by an animate entity, and such possessors are expressed as prefixes to the nouns. Similarly, animate Ps must be expressed as the core argument of Abui verbs.

\section{Summary and Discussion}

In Teiwa and Abui, the animacy of referents plays a crucial role in verbal and nominal agreement patterns. While verbal prefixes in Teiwa and Abui mark objects, not all objects are prefixed, so we cannot characterize the prefixing by referring to the grammatical role of the argument, nor does the semantic role of the argument play a determining role: non-agent argument of various kinds are prefixed. The traditional way to characterize agreement in terms of grammatical role or semantic properties (or a combination of these) is not adequate to describe the patterns found in Teiwa and Abui.

In both Teiwa and Abui, a structural relation exists between the object of verbs and the possessor of nouns: both arguments are expressed by identical prefixes, and when the referents are animate, the agreement is obligatory. Given the salient role that the animacy of entities plays in perception and cognition, it is not surprising that we find patterns like these where the animacy of a referent is the feature triggering verbal and nominal agreement.

In addition, similar connections have been noted in other languages. For example, polysemous possessive and benefactive morphemes are found in both Austronesian (Oceanic) as well as Papuan languages and are discussed in 


\section{The Role of Animacy in Teiwa and Abui (Papuan)}

Lichtenberk (2002). In Abui and Teiwa, the parallel goes even further, since in these languages not only benefactives, but all kinds of Ps are polysemous with possessors. $^{7}$

Finally, we would like to point out that animacy also plays a role in the agreement patterns in other grammatical domains of Papuan languages-for example, in the marking of the (single) object of verbs translated as 'give'. Many Papuan languages lack ditransitives altogether; many have at most one or two ditransitives (Foley 2000:377). ${ }^{8}$ In languages which have verbs for concepts like 'give', the object marker usually marks the recipient or benefactive, not the patient (Foley 2000:378). ${ }^{9}$ If we assume that animacy is the trigger for the marking of $\mathrm{P}$, a pattern like this is expected: a benefactive or recipient (the person given to) is by definition a human and thus marked on the verb more systematically and frequently than the patient (the thing given).

Another feature that is often mentioned as typical for Papuan languages is the existence of so-called 'experiential' constructions (Reesink 2002:27). In such constructions the experiencer of an uncontrolled state verb is marked by a regular object affix. This experiencer may be part of an intransitive construction ('me hungers'), or a transitive construction (e.g. 'it hungers me', 'hunger does me'). In these cases the experiencer, an animate non-agent, is marked like P, like the other non-agent animate arguments. ${ }^{10}$ Constructions like these exist in many Papuan languages and are additional indications that the animacy value of referents can play a pervasive role in shaping the agreement patterns of languages. ${ }^{11}$

\section{References}

Aissen, Judith. 2003. Differential Object Marking: Iconicity vs. Economy. Natural Language and Linguistic Theory 17:673-711.

Bittner, Maria, and Ken Hale. 1996. The Structural Determination of Case and Agreement. Linguistic Inquiry 27(1):1-68.

Bossong, Georg. 1991. Differential Object Marking in Romance and Beyond. In Douglas Kibbee and Dieter Wanner, eds., New Analyses in Roman Linguistics, 143-170. Amsterdam: John Benjamins.

\footnotetext{
${ }^{7}$ A Papuan language with similar patterns is Dani (spoken in the Balim Valley in the central part of West Papua), which also cross-references possessors and undergoers with identical forms. In Dani, forms with the vowel $o$ typically mark the inalienably possessed kinship terms and body parts (Bromley 1981:190), while alienably possessed nouns are marked with forms containing an $a$ root.

${ }^{8}$ For example, Teiwa has only one verb that optionally occurs with two objects in a ditransitive construction; all the other transitives are monotransitive.

${ }^{9}$ Often, the Patient occurs with its own predicate in a serial verb construction.

${ }^{10}$ In transitive constructions, the inanimate instigator of the experience is encoded like A.

${ }^{11}$ There may be other areas in Papuan languages where the animacy of a participant plays a crucial role. For example, it may determine the grammaticalization paths of certain verbs, as argued in Klamer (to appear).
} 


\section{Marian Klamer and František Kratochvíl}

Bromley, H. Myron. 1981. A Grammar of Lower Grand Valley Dani. Canberra: Research School of Pacific Studies, Australian National University.

Dowty, D. 1991. Thematic Proto-Roles and Argument Selection. Language 67(3):547-619.

Etherington, Paul A. 2002. Nggem Morphology and Syntax. M.A. thesis, The Northern Territory University, Australia.

Foley, William A. 2000. The Languages of New Guinea. Annual Review of Anthropology 29:357-404.

Gentner, Derdre, and Lera Boroditsky. 2001. Individuation, Relativity, and Early Word Learning. In Melissa Bowerman and Stephen C. Levinson, eds., Language Acquisition and Conceptual Development, 215-256. Cambridge: Cambridge University Press.

Klamer, Marian. In preparation. A Grammar of Teiwa.

Klamer, Marian. To appear. Animacy and the Grammaticalisation of 'come' in Teiwa and Kaera. In Michael Ewing and Marian Klamer, eds., Typological and Areal Analyses: Contributions from East Nusantara. Leiden: KITLV Press.

Kratochvíl, František. In preparation. A Grammar of Abui. Ph.D. diss., Leiden University.

Lichtenberk, Frantisek. 2002. The Possessive-Benefactive Connection. Oceanic Linguistics 41(2):439-474.

Ortmann, Albert. 1998. The Role of [+/-animate] in Inflection. In Ray Fabri, Albert Ortmann, and Teresa Parodi, eds., Models of Inflection, 60-84. Tübingen: M. Niemeyer.

Reesink, Ger. 1987. Structures and Their Functions in Usan, a Papuan Language of Papua New Guinea. Amsterdam: John Benjamins.

Reesink, Ger P. 2002. Languages of the Eastern Bird's Head. Canberra: Pacific Linguistics.

Van Valin, Robert D., and Randy J. LaPolla. 1997. Syntax: Structure, Meaning and Function. Cambridge: Cambridge University Press.

Marian Klamer

Leiden University

Languages and Cultures of SE Asia and Oceania

The Alor and Pantar Project (AAPP)

Faculty of Arts

P.O. Box 9515

2300 RA Leiden

The Netherlands

marian.klamer@let.leidenuniv.nl
František Kratochvíl

Leiden University

Languages and Cultures of SE Asia and Oceania

The Alor and Pantar Project (AAPP)

Faculty of Arts

P.O. Box 9515

2300 RA Leiden

The Netherlands

f.kratochvil@let.leidenuniv.nl 